\title{
2. Preparing for the 2006 enumeration at the Darwin Census Management Unit
}

\section{Frances Morphy}

\section{Introduction}

In broad organisational terms, a national census poses particular problems because of its scale and the five-year gap between census events. The Australian Bureau of Statistics (ABS) cannot keep on its permanent staff the thousands of people needed to coordinate the exercise on the ground and to distribute, collect and code the data from the forms. The 2006 Census exercise therefore involved the hiring of a temporary workforce of more than 42,000 people, who had to be trained adequately to carry out their allotted tasks. In such a context, the flow of information becomes vital - across time (so that the accumulated wisdom from previous census exercises is brought to bear on the organisation of the current one) and within the organisation itself, which is multi-sited and hierarchical.

One of the unique aspects of the research reported here is that it was itself multi-sited. This enabled us to observe aspects of the flow of information from the centre, the ABS headquarters in Canberra, to the periphery, the collector-interviewers (CIs) in four remote Aboriginal community settings, via the intermediate institution of the Census Management Unit (CMU) in Darwin, which was responsible for managing and planning the count in the Northern Territory, and its emissaries, the Census Field Officers (CFOs) and their Assistants, charged with responsibility for coordinating the count on the ground. We have also been able to observe the reverse flow after the count, from the ground back to Darwin and then back to the centre - in this case, the Data Processing Centre (DPC) in Melbourne.

This chapter is concerned primarily with the pre-enumeration flow of information from Canberra to Darwin and to the CFOs, and concentrates primarily on the pre-field training of the CFOs and on the information that was made available to them from Canberra and locally in Darwin.

The collection of census data from Indigenous people living in remote Australia is a dauntingly complex exercise. In recognition of this the ABS began, in the 1971 Census, to put in place a special Indigenous Enumeration Strategy (IES), which has subsequently been developed and finetuned with each successive census (see Taylor 2002). From the ABS's point of view, the remote count poses particular logistical problems because of the difficulty of access to the remotest small communities, the mobility of individuals within their regional networks, 
the low levels of English literacy of many Indigenous people and their relative unfamiliarity with and lack of understanding of the workings of the bureaucracy of the nation-state (instantiated in this case in the census exercise).

To ameliorate these problems, the IES uses CIs rather than expecting people to self-administer their forms. Ideally, the CIs are local people, so that advantage can be taken of their local knowledge, their knowledge of local languages and their familiarity with the interviewees. Ideally again, the CIs are selected and trained by the CFO in charge of the region with the help of local Community Coordinators (CCs). (The CCs might also act as CIs, but their main task is to help the $\mathrm{CFO}$ in coordinating the count in their community and managing the daily workloads of the CIs.)

In the Northern Territory - and in remote areas generally, such as parts of Western Australia - distance and remoteness, and the size of the areas that CFOs are responsible for, make it impossible to achieve a count in a single day. In the Northern Territory a time-extended 'rolling count' strategy is employed: notionally a CFO has between six and seven weeks to complete the count in their area of responsibility.

The CFOs, then, are a crucial link in the chain of information between the centre (the national guidelines of the census) and the periphery (the CIs on the ground). They are not permanent employees of the ABS, so must be trained from scratch. They have varying degrees of experience of working or living in remote Aboriginal localities and come from a variety of different working backgrounds. None of the 2006 CFOs in the Northern Territory had worked on a previous census. Their task is logistically complex and multifaceted, and the training they receive has a very direct bearing on the success or otherwise of the count-in terms of its completeness and of the quality of the resulting data.

\section{The sociopolitical context of the census}

In its instructions to the CFOs on how to frame the census to the Indigenous public, the ABS focuses on the census as a planning tool, used to 'identify the needs' for health or educational services, housing and so on in keeping with its view of itself as set out in its mission statement:

We assist and encourage informed decision-making, research and discussion within governments and the community, by providing a high quality, objective and responsive national statistical service. (Quoted in ABS 2006b: 3)

Perhaps for most census events this characterisation of the role of the ABS serves its purpose, but the 2006 Census - at least in the Northern Territory - took place in a politically charged environment, for two main reasons. The first was the furore over the almost realised political consequences of the 2001 count: the 
potential loss of a Northern Territory seat in the Commonwealth House of Representatives (Wilson et al. 2005). The second was the turbulent and changing state of Commonwealth Indigenous affairs policy, which was experiencing an upheaval of a magnitude not seen since the early 1970s. This was impacting directly on Indigenous communities and their organisations in unprecedented ways. Both these factors had an influence on the way in which the ABS and the census were perceived on the ground, and this will be a recurring theme in the pages that follow.

\section{The Community Housing and Infrastructure Needs Survey and the census}

Before considering the training for the census, I make a brief digression to comment on the Community, Housing and Infrastructure Needs Survey (CHINS), which the ABS conducted again in 2006 on behalf of the Department of Family and Community Services (FaCS, now FaCSIA). This too was in the job remit of the CFOs. On the ABS website, the CHINS work is portrayed as complementary to - and possibly helpful to - the conduct of the census itself: 'To minimise disruption in communities, CHINS visits to communities will be combined with visits to consult on arrangements for the 2006 Census' (http://www.abs.gov.au, accessed 12 February 2006).

At the Darwin CMU, the CFOs were trained first to conduct the CHINS in their region, and one day of training on the census - concerned mainly with pre-census arrangements - was added at the end of that week. They then went out to conduct CHINS before returning to Darwin for the fully fledged census training. I attended the one-day census training day and the full census training.

The CHINS and census exercises are quite different, and arguably require different skill sets on the part of the CFOs (this opinion was put to me in retrospect by CMU staff) - at least under the current IES arrangements. In CHINS, the CFOs' major contact is with staff of Indigenous Housing Organisations (IHOs) rather than directly with community members, and their work is largely office based. For the census, on the other hand, the CFOs and their Assistants had the responsibility for recruiting, training and managing the CCs and CIs, as employees of the ABS. ${ }^{\text {l }}$ This is a potential source of tension at the community level (see, in particular, Chapter 5).

1 During their training, the CFOs had one session on the new initiative put in place by the Northern Territory government in partnership with the ABS, in which community volunteers - such as local teachers and health staff- were being trained and encouraged to provide logistical support to the CFOs and their teams. Some CFOs reported early teething troubles with the implementation of this initiative, in which some volunteers were exceeding the bounds of their duties and attempting to play a role in the recruiting of CIs and in organising the count. They also reported confusion at the community level between the roles of the volunteers and the CIs, with people believing that the CI role was to be an unpaid one. These facts, too, contributed to the feeling among the CFOs that the boundaries between ABS staff and others needed to be demarcated clearly. In the event, no volunteers were forthcoming in 
On their return to Darwin after undertaking the CHINS, the CFOs' first day of the training for the census consisted of a debriefing on the CHINS exercise. The CFOs were generally of the opinion that, far from assisting with the census, the CHINS exercise got in the way of their attempts to prepare for the census count.

\section{The Discrete Indigenous Communities Database}

The problems caused by the CHINS were compounded by the request that was put to CFOs - and that had been covered only briefly at the end of the CHINS training - to fill in a detailed Indigenous Community Information form for each community they visited. It was the first time that a form of this type had been used.

In the debriefing, the CFOs commented that this was a big task that had been given to them at the last minute, and that the instructions about the status of the form were unclear. Some said it had interfered substantially with their ability to undertake census promotion activities. The form was time-consuming to fill in and CFOs had felt reluctant to take up more of people's time after doing the CHINS exercise. Some organisations were reluctant to cooperate, saying that this kind of information was already being collected and held by other agencies, and expressing distrust about the uses to which the information would be put. The CFOs had therefore mostly not completed them fully.

The information from these forms is to be fed into a Discrete Indigenous Communities Database (DICD) that will be maintained by the ABS's National Centre for Aboriginal and Torres Strait Islander Statistics (NCATSIS) section and will be for ABS internal use only. If properly maintained and updated, it will provide invaluable background information for subsequent surveys and censuses. The form and the necessity to fill it out for each community was mentioned in the written instructions to the CFOs about their roles and responsibilities, so possibly this indicates that - like the CCs and CIs - the CFOs did not make much reference to their written instructions. More charitably, given the amount of information and documentation that they have to absorb, more thought needs to be given in the training sessions to highlighting information that is considered crucial.

As noted above, this particular census took place in the context of considerable changes in the policy settings in Indigenous affairs, and many community organisations were under extreme pressure and were feeling somewhat distrustful of government intentions. In such a context, it appears to have been difficult for the CFOs to persuade them that the ABS, although a government agency,

the area where I made my observations (see Chapter 4), and I cannot report directly on the success or otherwise of the volunteer initiative. Some CFOs commented that the initiative had worked well in their communities. 
was not government per se, and that much of the data it gathered was for internal purposes only.

\section{The training of the Census Field Officers for the census}

This section on the training received by the CFOs in Darwin must be read in context: the training is being evaluated with the benefit of hindsight. I will tend to focus on those aspects of the training that did not prepare the CFOs adequately for their task, in order to provide useful feedback to inform the training process for 2011. I want to stress at the outset that there were many positive aspects to the training, not least the amount of time and effort that went into preparing the training materials and the openness of the CMU staff to comments and suggestions from the CFOs and Assistant CFOs.

\section{The value of local knowledge}

None of the CMU staff involved in managing the conduct of the IES in 2006 had been a part of the CMU in 2001. They were therefore heavily reliant on the advice and training materials provided by the central office, and on gleaning information from those people at the CMU who had experience of the count in 2001 .

It is my impression that the practical knowledge and experience gained on the ground in successive censuses is fed back to Canberra in the form of reports from the CFOs and CMU staff, and it then informs central planning for the next census. It appeared to me, however, that very little of that practical knowledge and experience had been preserved at the local level from 2001. In other words, there appeared to be little institutional memory at the local level for the CFOs to draw on. The information that comes from the centre is informed by past experience, but the reasoning behind decisions that have been made is opaque to those who then have to use that information locally. They are presented in the training with a plethora of procedures and forms, with little sense of the real-life contexts in which they are going to be using them.

For example, it would have been invaluable to the CFO in charge of the eastern Arnhem Land region (see Chapter 4) to have access to the journal-or an edited version of the journal - of the CFO who had been in charge of that same area in 2001. The CFO for 2006 would then have had the benefit of the local knowledge gained by his predecessor and also the opportunity to learn from his mistakes and build on his successes. This information, together with updated forms for each community from the DICD, would give the CFOs a much better 'feel' for the real-life contexts in which they would be operating, and would give them a context in which to understand the procedural details on which the training inevitably focused in an exercise as complex as the census. 


\section{Imparting information: instruction and practical application}

In the first part of the training session for the census, the CMU staff asked for feedback from the CFOs on the CHINS training that they had received. The CFOs were quite critical, feeling that the training period had been too compressed and that there had been too much delivery of information in a lecture format and not enough practical scenarios. They felt there had been too much emphasis on procedural matters and not enough on the content of the survey instrument. For example, the ABS definition of 'temporary dwelling' differs from the one used by other agencies, and this caused some problems with IHOs because funding is dependent on such definitions.

The general tenor of these comments also applied to the census training itself. It too was very concentrated and the information was presented in a highly condensed way, with little opportunity for the CFOs to practice what they were being taught. Rather than concentrating the training into a solid block, it would have been more effective to have half-day or one-day sessions spread over several weeks, concentrating on one aspect of the exercise at a time. One of the regional managers delivering the training commented to me that if people had read all the documentation they had been provided with before the training, not so much time would have been spent on unimportant questions. The trouble was that there was an enormous amount of documentation. If the training had been broken up into smaller blocks it would have been possible to ask the CFOs to review the documentation for that topic alone before the training session, and then re-enforce and amplify the written materials. This would have been a more effective way of ensuring that they were familiar with those materials.

Breaking the training into blocks would also allow time for practical sessions in which the CFOs would have the opportunity to consolidate their understanding. Scenarios would have been particularly beneficial in the session on providing training to the CCs and CIs. Most of the CFOs were not trained 'trainers', as they commented themselves. Giving them practical experience-by asking them to practice delivering training to one another in a mock tutorial - would have been an effective way of building their practical experience, supplementing the information that they were given on different 'learning styles' ${ }^{2}$ This information, although interesting in itself, was not presented in such a way as to feed into the practical situation of a training session.

The focus throughout the training was on processes and administrative procedures. This was understandable, particularly in view of the complexities involved in some procedural matters - for example, the payment system for CCs

2 Indeed, as I learned subsequently from a member of the CMU staff who had been involved in the 2001 IES in Darwin, this was how the 'training' training was delivered in 2001. 
and CIs. ${ }^{3}$ One overriding concern - that the count should be as accurate as possible and be seen to be accurate-dominated the discourse. The focus on this concern had two effects. The emphasis on the 'head count' aspect of the census meant that the details of the questions on the Interviewer Houshold Form (IHF) received relatively little emphasis. And the focus on checking the count against other data - such as the 2001 Census, the 2006 CHINS and any administrative data that the CFOs could access - in order to assess the accuracy of the count led to a de-emphasis on strategies for getting a complete count in the first place. As a consequence, certain issues that turned out to be of crucial importance on the ground received only cursory treatment in training. With the benefit of hindsight, I will focus on the most significant of these: the question of how to treat 'persons temporarily absent' (PTA).

\section{Persons Temporarily Absent}

The intention of the ABS in 2006 was to carry out - as far as possible - a de facto count of the people in dwellings in discrete Indigenous communities. From past experience, however, it was known that some exceptions would have to be made, to cover people who were absent temporarily and who might not be counted elsewhere. In the Census Field Officer Manual for the 2006 Census, the following instructions were given with regard to absent people and vacant dwellings:

\subsubsection{Absent People}

- Any people who usually live in the dwelling but are away at the time of the Census should be listed in the Table for Persons Temporarily Absent on page 3 of the Interviewer Household form, unless they are at a place where they are unlikely to be put on a Census form, such as the bush or fishing.

To avoid either double-counting or missing individuals, the following rule is applied to people who were absent from the household at the time of the census:

- If they were at a place where they would have been counted on a different Census form, such as a town or another community, the person should only be included in the Table for Persons Temporarily Absent.

- If they were at a place where they would not have been counted, such as camping in the bush, travelling, or on other cultural or business activities, the person should be listed on page 4 with the people staying in the dwelling

\footnotetext{
3 The payment system had received some close attention between 2001 and 2006 and the form-filling aspect of it was, in fact, more streamlined. It continues to be problematic, however - perhaps inevitably so. Radical simplification would entail a move away from the present centralised system of payment, and this, presumably, is not possible.
} 
at the time of the Census, and all other questions in the form should be answered for the person as though they were there.

\subsubsection{Vacant dwellings}

If the Collector-Interviewer comes across any dwellings in their workload where no one is staying, they should complete the front page and questions 2-3 of the Interviewer Household Form. The rest of the form is left blank.

In the CFO training notes for the training of the collector-interviewers, a further distinction is made:

\section{Counting an unoccupied dwelling}

Explain: If you come across a dwelling that no one lives in (an empty place), you should fill in an Interviewer Household Form for that dwelling, answering questions 2 and 3 only. This includes dwellings that are unoccupied for cultural reasons.

\section{Counting an occupied dwelling where no one is home}

Explain: If you visit a dwelling where people usually live and find there is no one home, try to find out whether they will be back before the Census is finished. If they do come back, complete the forms. If no one returns during the Census time, the dwelling is counted as an unoccupied dwelling (empty place).

During their training, the CFOs flagged PTA and the rules for dealing with them as something that was worrying them. One of them said, "This is the issue that has been jumping off the page for $\mathrm{me}^{\prime}$, and they all wanted to spend more time on this topic. Their main concern was how one could know for sure that a PTA had been counted elsewhere, given the rolling nature of the count. They pointed out that the local knowledge of the CCs and CIs would be of little use here, since there was no way those people could know whether or not someone had been counted elsewhere. The general advice given was, if in doubt, include the person in the main part of the form as if they were present, and get as many details as possible for them. In the event, not a great deal of time was spent on the topic, because, in the absence of a detailed compendium of the kinds of scenarios that might occur, the discussion could not be framed in a useful way. There just seemed to be endless possible scenarios, each less clear-cut than the last.

The case-study chapters (3-6) show that the CFOs were right to be worried about this question. In the training of CCs and CIs that I observed in Arnhem Land, the CFO was not able to articulate a plan of action for the CCs and the CIs that was any clearer than the instructions he had received himself. As is argued in Appendix B, the design of the form itself tended to lead CCs and CIs to leave 
PTAs out of the main body of the form, and the lack of training on how to make judgments to do otherwise certainly compounded this tendency. I return to the consequences in the discussion of the post-count phase at the CMU (Chapter 7).

\section{Logistics}

In talking to the CFOs about logistics, the CMU staff was constrained by the time frames that had been set by the ABS in Canberra. The CFOs were expected to have the CC and CI training, the count itself and the post-count checking completed and all the forms back to Darwin in six to seven weeks (10 July-28 August). After their CHINS experience, it was clear that most of them considered this to be unrealistic - and, as it turned out, they were right. The CMU staff was in a position in which they had to maintain the idea that everything could be done realistically within the time frame that had been set. It was clear, however, that they also had their doubts: it was said that the most important thing was to get as good a count as possible, and that if the worst came to the worst that took precedence over deadlines. They had also put into place 'emergency backup' provisions, with a 'floating' CFO who could be called in to help in areas where things were going slowly. The net effect was a tendency to curtail discussion about possible problems and to 'focus on the positives' to a somewhat sceptical audience of CFOs. I felt this situation is hard on the CMU staff and the CFOs, and that Canberra needs to take on board the fact that the IES - as it is presently organised — cannot be undertaken in the envisaged time frame.

\section{Conclusion}

This chapter concludes with some recommendations that would apply equally if the IES were to remain substantially the same as it is now, or, alternatively, if it were to be overhauled radically in the manner we recommend (see Chapter 9).

The way in which information about local conditions is preserved from census to census, and the availability of such information to those who most need it (the CFOs), could be vastly improved. One tool in the future armoury will be the DICD, but it will be useful only if it is updated constantly. This task should be decentralised to augmented Indigenous Liaison Units within the ABS regional offices in all States and Territories where the IES is implemented.

The detailed reports of the CFOs and CMU staff from the 2001 census should not only be analysed centrally in Canberra; they should be available, perhaps in edited form with commentary, to the CMU staff and CFOs employed for the subsequent census. Given that each region - or even community - has its own characteristics, substantive information about logistical problems and solutions, about the mobility patterns of regional populations and about cultural factors specific to particular regions would be of particular value. Such information would give the CFOs a 'feel' for the size of the task and for the local conditions 
they might encounter. This kind of information cannot be imparted formally and in abstract in the very compressed training time that is available.

The sheer number of different kinds of information that the CFOs have to master needs to be taken into account more fully in the training methods employed. It would be useful - and less daunting for the participants (CFOs and CMU staff) - to break the training up into more manageable chunks, allowing the CFOs the opportunity to focus on just one topic at a time. This would allow them to absorb the relevant written materials more effectively beforehand, and have that information reinforced during training. It would also give more scope for acting out scenarios, rather than just having the information delivered in lecture format. Such scenario-building, as well as giving people practical experience, is likely to throw up omissions or lack of clarity in the written materials. These can then be addressed before people go out into the field, lessening the likelihood of ad hoc and possibly inconsistent solutions being implemented on the run out in the field.

In the training that was delivered to the CFOs in 2006, there was a great deal of emphasis - necessarily so - on procedural matters and on the 'head count' aspect of the census. For the latter, however, there was an inadequate anticipation of the scale and complexity of the PTA problem and of the difficulties likely to be caused by the time-extended and rolling nature of the count (see following chapters). Documentation of the PTA phenomena encountered and how they were dealt with in 2006 should be analysed carefully at central and State/Territory levels, so that future training on this question can be better informed.

Matters of content and definition received relatively little emphasis in training. In particular, the IHF - the collection instrument - is itself a complex document that needs careful and detailed explication. It must be remembered that census questions are framed in terms of categories devised by the ABS, which in turn reflect the planning and policy concerns of the nation-state and its agencies. These concerns and categories are not necessarily transparent to the CFOs, let alone to the CCs, CIs and individual respondents. ${ }^{4}$ In order for the CFOs to train the CCs and CIs in an informed manner, it is necessary for them to understand the content and structure of the questions, and the nature of the information they are intended to elicit. In the future, if the CC role is augmented in the

\footnotetext{
4 For example, one CFO questioned the utility of Questions 30 and 31, which ask whether the person's mother/father is in the dwelling, and also ask for the parents' 'person numbers' (see Appendix A). He thought these questions were redundant in view of the fact that information about relationships between household members and Person 1 had been elicited earlier in the form. In fact, these questions had been added to the form in order to elicit a finer-grained account of the internal structures of households, replacing a much less successful question on the 2001 form concerning an individual to whom the person was 'more closely related' than they were to Person 1. Once this was explained, the CFO saw the point of the questions and the value of asking them.
} 
manner in which we have suggested in the concluding chapter, it will be possible also to train the CCs to this level of understanding. 